\title{
Prevention of Traditional NSAID-Induced Small Intestinal Injury: Recent Preliminary Studies Using Capsule Endoscopy
}

\author{
Shunji Fujimori Yoko Takahashi Tsuguhiko Seo Katya Gudis Akihito Ehara \\ Tsuyoshi Kobayashi Keigo Mitsui Masaoki Yonezawa Shu Tanaka \\ Atsushi Tatsuguchi Choitsu Sakamoto
}

Department of Internal Medicine, Division of Gastroenterology, Nippon Medical School, Tokyo, Japan

\section{Key Words}

Small intestine $\cdot$ Non-steroidal anti-inflammatory drugs •

Prostaglandin $\cdot$ NSAID small bowel injury, prevention .

Capsule endoscopy

\begin{abstract}
Capsule endoscopy and balloon endoscopy, advanced modalities that now allow for full investigation of the entire small intestine, have revealed that non-steroidal anti-inflammatory drugs (NSAIDs) can cause a variety of abnormalities in the small intestine. Traditional NSAIDs can induce small intestinal injuries in over $50 \%$ of patients. Several studies have shown that the preventive effect of proton pump inhibitors does not extend to the small intestine, suggesting that concomitant therapy may be required to prevent small intestinal side effects associated with traditional NSAIDs use. Recently, several randomized controlled trials used capsule endoscopy to evaluate the preventive effect of certain drugs on NSAID-induced small intestinal injuries. These studies show that misoprostol and rebamipide have a preventive effect for NSAIDinduced small intestinal mucosal injuries. However, these studies included only a small series of healthy volunteers and tested short-term NSAID treatment. Therefore, further extensive studies are clearly required to ascertain the beneficial effect of these drugs.

Copyright $\odot 2010$ S. Karger AG, Basel
\end{abstract}

\section{Introduction}

Non-steroidal anti-inflammatory drugs (NSAIDs) are among the most commonly prescribed drugs worldwide. They are widely used to help relieve musculoskeletal pain and inflammation, but can cause serious upper gastrointestinal side effects including dyspepsia, peptic ulceration, and hemorrhage $[1,2]$. Until recently, most studies on NSAID-associated injury have focused on the upper gastrointestinal tract, since the stomach and duodenum are the sites generally associated with major morbidity and mortality in the clinical setting. However, epidemiological studies suggest that NSAIDs may also increase the risk for lower gastrointestinal adverse events $[3,4]$. One recent prospective trial showed that serious lower gastrointestinal events in rheumatoid arthritis patients taking NSAIDs may account for $40 \%$ of all serious gastrointestinal events that develop in these patients [5]. In addition, capsule endoscopy and double-balloon endoscopy $[6,7]$, advanced modalities that now allow for full investigation of the entire small intestine, have revealed that NSAIDs can cause a variety of abnormalities in the small intestine such as ulcerations, perforation, bleeding and diaphragmlike stricture $[3,4,8-10]$.

\section{KARGER}

Fax +4161306 1234 E-Mail karger@karger.ch www.karger.com
Shunji Fujimori, MD, PhD

Division of Gastroenterology, Department of Internal Medicine

Nippon Medical School, 1-1-5, Sendagi, Bunkyo-ku

Tokyo 113-8603 (Japan)

Tel. +81 33822 2131, Fax +81 35685 1793, E-Mail s-fujimori@nms.ac.jp 


\section{Prevalence of NSAID-Induced Small Intestinal Injury}

Indium-111-labeled white blood scintigraphy detected small intestinal inflammation in more than $50 \%$ of chronic NSAID users, and fecal tests found signs of intestinal permeability and inflammation in $44 \%$ of this class of patients [11]. Morris et al. [8] showed ulcerations by sonde enteroscopy in 7 of 15 (47\%) rheumatoid arthritis patients on NSAID medication. In a recent study, Maiden et al. [12] found new intestinal lesions by capsule endoscopy in $68 \%$ of healthy volunteers who took NSAIDs for 2 weeks. Goldstein et al. [13] reported that $55 \%$ of subjects developed small intestinal injuries after 2 weeks of naproxen medication, with a mean of 2.99 mucosal breaks per subject. In Japan, small intestinal mucosal breaks were detected by double-balloon endoscopy in $51 \%$ of the NSAID users and $5 \%$ of those not taking NSAIDs [10].

\section{Key Process of NSAID-Induced Small Intestinal Injury}

NSAIDs are known to increase intestinal permeability, the magnitude of which is quantitatively related to the potency of their ability to inhibit cyclooxygenase (COX)1 [14]. The precise mechanism by which the inhibition of COX by NSAIDs translates into injury of the small intestine is poorly understood. Nevertheless, the first step leading to small intestinal mucosal injury is considered to be the topical toxicity of NSAIDs, which induces the uncoupling of mitochondrial oxidative phosphorylation in epithelial cells [15]. This topical action is followed by increased mucosal permeability and inflammation [16], which appears to be a prerequisite for NSAID-induced small intestinal injury and ulceration. However, it has been clearly shown that COX-1 inhibition is also required to convert topical toxicity into ulcerative damage. Somasundaram et al. [16] have shown that co-administration of aspirin, a COX-1 inhibitor that is mainly absorbed through the stomach and duodenum, and dinitrophenol, which increases intestinal permeability through the disruption of mitochondrial activity, induces intestinal ulceration similar to that induced by indomethacin. These data suggest that the inhibition of COX-1 is likely to be a key process in intestinal ulceration. Nevertheless, it is still far from clear exactly how COX-1 is involved in the key process of intestinal ulceration.

\section{COX-2 Inhibitor or Proton Pump Inhibitor for Small Intestinal Injury}

Capsule endoscopy studies have shown that even concomitant administration of proton pump inhibitors failed to prevent NSAID-induced small intestinal injury in healthy volunteers $[12,13]$. As for the prevention of NSAID-induced small intestinal injury, several studies have already shown that celecoxib, a selective COX-2 inhibitor, effectively reduces both the number of mucosal breaks per subject and the percentage of subjects with at least 1 mucosal break $[13,17]$. COX-2 inhibitors were initially introduced to provide symptomatic pain relief along with reduced gastrointestinal risk. However, in 2005, a joint hearing of the US Food and Drug Administration Arthritis Committee and the Drug Safety and Risk Management Committee found that the use of COX2 inhibitors is associated with increased risk of cardiovascular events. These recent events have led many physicians to consider the use of traditional NSAIDs in combination with a proton pump inhibitor, a recommendation found in major treatment guidelines for patients with a history of gastrointestinal events or for those at high risk of developing complications [4]. Indeed, many physicians are again using traditional NSAIDs in combination with proton pump inhibitors as the preferred preventive method against NSAID-induced gastrointestinal injury [18, 19]. However, studies have shown that the preventive effect of proton pump inhibitors does not extend to the small intestine, suggesting that concomitant therapy may be required to prevent small intestinal side effects associated with NSAID use. The recent studies of prevention of traditional NSAID-induced small intestinal injuries are introduced below.

\section{Effects of Various Drugs on NSAID-Induced Small Intestinal Injury}

\section{Prostaglandin (Misoprostol)}

It has been suggested that NSAID-induced inhibition of COX-1, a key molecule that catalyzes prostaglandin (PG) production, is involved in the disruption of the protective mechanism in the gastric mucosa [18]. It is widely known that PG is effective in preventing NSAID-induced gastric mucosal injury [19-21]. As for NSAID-induced small intestinal injuries, a sequence of events, such as an increase in the permeability of epithelial cells due to the direct toxic effect of NSAIDs, bacterial translocation, and inflammation through cytokine activation in the small

Fujimori et al. 
intestinal mucosa, have been suggested to be key elements in the induction of small intestinal ulceration in addition to a lack of PG $[15,16,22]$. As for injury to the small intestine, PG has been shown to reverse NSAIDinduced changes in intestinal permeability, a local intestinal event that is considered to play a pivotal role in inflammation and injury [23]. Furthermore, the co-administration of misoprostol, a $\mathrm{PGE}_{1}$ analog, has been shown to attenuate the effect of NSAIDs on intestinal permeability in humans [23]. Therefore, we investigated the effect of misoprostol on small intestinal injury induced by traditional NSAID (diclofenac) in a single-blind, randomized controlled study [24].

\section{Capsule Endoscopy Study}

Thirty-four healthy male volunteers were screened by capsule endoscopy. All eligible subjects $(n=32)$ were randomly divided into an NSAID-control group $(\mathrm{n}=16)$ and NSAID-PG group $(n=16)$. All eligible subjects were administered diclofenac ( $75 \mathrm{mg} /$ day) and omeprazole (20 $\mathrm{mg} /$ day) for a period of 2 weeks, and the NSAID-PG group assigned to receive misoprostol (600 $\mu \mathrm{g} /$ day) in addition to the original treatment. In this study, we calculated mucosal breaks in the small intestine to be defined as lesions with slough surrounding erythema. Examples of typical mucosal breaks are shown in figure 1. A total of 15 NSAID-control subjects and 15 NSAID-PG subjects completed the treatment; the entire small intestine of each subject was evaluated by capsule endoscopy. In the NSAID-control group, 2 weeks of NSAID treatment induced 44 mucosal breaks in 8 subjects, resulting in a mean of $2.9 \pm 6.3$ mucosal breaks per subject. In the NSAID-PG group, PG treatment reduced the number of mucosal breaks to 10 in 2 subjects (mean $0.7 \pm 2.3$ ). Thus, at post-treatment capsule endoscopy, the mean number of mucosal breaks per subject was significantly higher in the NSAID-control group than in the NSAID-PG group $(\mathrm{p}=0.028)$. The percentage of subjects with at least $1 \mathrm{mu}-$ cosal break at post-treatment was also significantly higher in the NSAID-control group (53.3\%) than in the NSAID-PG group (13.3\%) $(\mathrm{p}=0.002)$. Three subjects in the NSAID-PG group and 1 subject in the NSAID-control group complained of slight diarrhea at the beginning of treatment [24].

In the present study, misoprostol was effective in preventing the development of small intestinal mucosal breaks in healthy individuals receiving a 2 -week regimen of diclofenac. The percentage of subjects that were found to have mucosal breaks at baseline endoscopy was $10 \%$ in the present study, compared to reports of $7-14 \%$ in other studies, indicating that co-administration of misoprostol can reduce the development of mucosal breaks in patients on NSAID medication down to approximately basal levels [13, 17, 25]. Taking into consideration previous reports and our data, it is likely that misoprostol can prevent both upper and small intestinal injuries associated with the use of traditional NSAIDs. Moreover, Watanabe et al. [26] reported that misoprostol $(800 \mu \mathrm{g} / \mathrm{day})$ prevented lowdose enteric-coated aspirin (100 mg/day)-induced small intestinal injuries in 4 out of 7 patients. There is a possibility that misoprostol can prevent not only NSAID- but also aspirin-induced small intestinal injury.

\section{Rebamipide}

As previously mentioned, the authors have shown that co-administration of misoprostol reduced the incidence of small intestinal lesions induced by 2 -week administration of diclofenac [24]. However, misoprostol can induce intolerable side effects as reported previously [27]. Rebamipide has been used across Asia for the treatment of gastric ulcers and gastric lesions such as erosions and edema caused by acute gastritis [27-29]. It has been well documented that rebamipide increases endogenous PG levels, scavenges free radicals, and suppresses inflammation in the gastric mucosa $[11,30,31]$. Through these actions, rebamipide has been also shown to be useful in preventing NSAID-induced gastrointestinal injuries in clinical studies and animal experiments. In a randomized controlled trial of rheumatoid arthritis and osteoarthritis patients carried out in East Asian countries, the effectiveness of rebamipide was shown to equal that of misoprostol in preventing the incidence ratio of gastroduodenal ulcers caused by 12 weeks of NSAID medication [31]. In an animal experiment, rebamipide has been shown to inhibit increases in iNOS activity induced by indomethacin, thereby reducing small intestinal injury caused by NSAIDs in rats [32]. From all these data, it is reasonable to speculate that to some extent, rebamipide might serve to reduce small intestinal damage in patients on NSAID medication.

\section{Capsule Endoscopy Studies}

A preliminary study recently conducted by Niwa et al. [33] has shown that rebamipide effectively reduced the incidence of NSAID-induced small intestinal injury. Their positive data were obtained in a double-blind, randomized, cross-over study where subjects were treated with diclofenac (75 mg/day) and omeprazole $(20 \mathrm{mg})$ in the presence or absence of rebamipide ( $300 \mathrm{mg} /$ day) for 7 days. The study shows that the number of subjects with 
1

Fig. 1. Example of a typical mucosal break. Mucosal breaks were defined as lesions with slough surrounded by erythema.

Fig. 2. Example of a typical denuded area. Denuded areas were defined as reddened areas without villi.
2

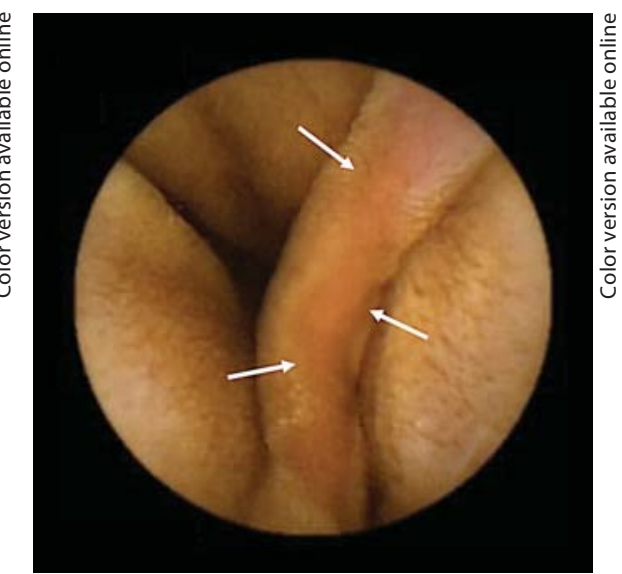

Table 1. Randomized controlled trials using capsule endoscopy evaluated prevention therapy for traditional NSAID-induced small intestinal injuries

\begin{tabular}{|c|c|c|c|c|c|c|c|c|c|c|}
\hline \multirow[t]{2}{*}{ Reports } & \multirow[t]{2}{*}{$\mathrm{n}$} & \multirow{2}{*}{$\begin{array}{l}\text { Drop- } \\
\text { out }\end{array}$} & \multirow[t]{2}{*}{ Study design } & \multirow[t]{2}{*}{ NSAID } & \multirow[t]{2}{*}{ Evaluated drug } & \multirow[t]{2}{*}{ Period } & \multirow{2}{*}{$\begin{array}{l}\text { Evaluated } \\
\text { injuries }\end{array}$} & \multicolumn{2}{|c|}{ Ratio of subjects with injuries } & \multirow[t]{2}{*}{ Evaluation } \\
\hline & & & & & & & & control & treatment & \\
\hline $\begin{array}{l}\text { Fujimori } \\
\text { et al. [24] }\end{array}$ & 34 & 4 & single-blind & diclofenac & misoprostol & 14 & mucosal break & $53 \%(8 / 15)$ & $13 \%(2 / 15)$ & effective \\
\hline $\begin{array}{l}\text { Niwa } \\
\text { et al. [33] }\end{array}$ & 10 & 0 & $\begin{array}{l}\text { double-blind, } \\
\text { cross-over }\end{array}$ & diclofenac & rebamipide & 7 & $\begin{array}{l}\text { mucosal break } \\
\text { bleeding, redness }\end{array}$ & $80 \%(8 / 10)$ & $20 \%(2 / 10)$ & effective \\
\hline $\begin{array}{l}\text { Fujimori } \\
\text { et al. [34] }\end{array}$ & 80 & 8 & double-blind & diclofenac & rebamipide & 14 & $\begin{array}{l}\text { mucosal break, } \\
\text { denuded area }\end{array}$ & $63 \%(24 / 38)$ & $47 \%(16 / 34)$ & $\begin{array}{l}\text { injuries } \\
\text { decreased }\end{array}$ \\
\hline $\begin{array}{l}\text { Niwa } \\
\text { et al. [36] }\end{array}$ & 10 & 0 & $\begin{array}{l}\text { double-blind, } \\
\text { cross-over }\end{array}$ & diclofenac & geranylgeranylacetone & 7 & $\begin{array}{l}\text { mucosal break } \\
\text { bleeding, redness }\end{array}$ & $40 \%(4 / 10)$ & $10 \%(1 / 10)$ & $\begin{array}{l}\text { no statistical } \\
\text { difference }^{\mathrm{a}}\end{array}$ \\
\hline
\end{tabular}

${ }^{a}$ Geranylgeranylacetone reduced diclofenac-induced gastric and small intestinal injuries in all.

small intestinal mucosal injuries was higher in the placebo group (8/10) than in the rebamipide group $(2 / 10)$ $(\mathrm{p}=0.023)$. However, the study is notably small in size, with only 10 subjects. Therefore, we conducted a larger sample size study to re-evaluate the effect of rebamipide on diclofenac-induced small intestinal injuries in healthy subjects, in a double-blind, randomized controlled trial.

Eighty healthy male volunteers were randomly divided into a placebo group $(\mathrm{n}=40)$ and a rebamipide group $(\mathrm{n}=40)$. After evaluation by baseline capsule endoscopy, all eligible subjects were administered diclofenac and omeprazole for a period of 2 weeks. The placebo group was assigned to remain on the original diclofenac and omeprazole therapy with a placebo capsule, while the rebamipide group was assigned to receive a capsule filled with rebamipide in addition to the original treatment.
These doses were the same as in the previous study [34]. A total of 38 control subjects and 34 rebamipide subjects completed the treatment and were evaluated by capsule endoscopy. NSAID therapy increased the mean number of mucosal injuries per subject, from a basal level of 0.1 \pm 0.3 to $15.9 \pm 71.6$ and $4.2 \pm 7.8$ in the control and rebamipide co-treatment groups, respectively, the difference between the two groups was not significant. Mucosal injuries consisted of both mucosal breaks (fig. 1) and denuded areas (fig. 2) in this study. These lesions are not associated with each other [35]. The difference in the percentage of subjects with at least one mucosal injury at post-treatment was also not significant (control 63\%, rebamipide 47\%). However, when we limited our analysis to subjects with mucosal injuries, rebamipide co-treatment significantly reduced the mean number of mucosal inju- 
ries per subject, from $25.1 \pm 89.3$ in the placebo group to $8.9 \pm 9.4$ in the rebamipide group $(p=0.038)$. We found that rebamipide reduced the intensity of injury in subjects apparently susceptible to NSAID-induced small intestinal injuries. These data were presented at Digestive Disease Week 2009 in Chicago [34].

\section{Other Drugs}

Niwa et al. [36] also reported that geranylgeranylacetone reduced diclofenac-induced gastric and small intestinal injuries in all from $9.5 \pm 8.5$ in the placebo group to $2.6 \pm 3.2$ in the geranylgeranylacetone group evaluated by capsule endoscopy $(\mathrm{p}=0.027)$. Analysis was limited to small intestinal injuries; the difference between the two groups was not significant. The data were obtained in a double-blind, randomized, cross-over study where subjects were treated with diclofenac and omeprazole in the presence or absence of geranylgeranylacetone (300 $\mathrm{mg} /$ day) for 7 days. Geranylgeranylacetone is a gastric mucosal-protective agent that is widely used in Japan and other Asian countries for the treatment of gastritis and gastric ulcers $[37,38]$. Table 1 shows these four randomized trials using capsule endoscopy. Marchbank et al. [39] reported that Pacific whiting fish hydrolysate prevented indomethacin-induced permeability increasing. The study did not employ capsule endoscopy. Fish hydrolysate is claimed to be beneficial for a variety of gastrointestinal conditions, and the study showed it to be capable of stimulating proliferation and migration of HT29 cells in vitro [40]. Data were obtained in a double-blind, randomized, cross-over study where subjects were treated with indomethacin ( $50 \mathrm{mg} /$ day) for 5 days in the presence or absence of fish hydrolysate starting 2 days prior to indomethacin.

\section{Conclusion}

Although these trials found that misoprostol, rebamipide and fish hydrolysate were effective agents against the development of NSAID-induced small intestinal injury, the inherent limitations of these studies preclude the drawing of any firm conclusions. Firstly, these studies included only a small number of healthy volunteers. Secondly, the short-term NSAIDs and treatment tested is not typical of the clinical setting, where longterm NSAID therapies are the norm. Therefore, further extensive studies are clearly required to ascertain the beneficial effect of these drugs.

\section{Disclosure Statement}

The authors declare that no financial or other conflicts of interest exist in relation to the content of the article.

\section{References}

1 Fries JF, Williams CA, Bloch DA, Michel BA: Non-steroidal anti-inflammatory drug-associated gastropathy: incidence and risk factor models. Am J Med 1991;91:213-222.

-2 Smalley WE, Ray WA, Daugherty JR, Griffin MR: Nonsteroidal anti-inflammatory drugs and the incidence of hospitalizations for peptic ulcer disease in elderly persons. Am J Epidemiol 1995;141:539-545.

-3 Allison MC, Howatson AG, Torrance CJ, Lee FD, Russell RI: Gastrointestinal damage associated with the use of nonsteroidal antiinflammatory drugs. N Engl J Med 1992;327: 749-754.

4 Bjarnason I, Hayllar J, MacPherson AJ, Russell AS: Side effects of non-steroidal anti-inflammatory drugs on the small and large intestine in humans. Gastroenterology 1993; 104:1832-1847.

5 Morris AJ, MacKenzie JF: Small bowel enteroscopy in undiagnosed gastrointestinal blood loss. Gut 1992;33:887-889.
6 Iddan G, Meron G, Glukhorsky A, Swain P: Wireless capsule endoscopy. Nature 2000 405:417.

7 Yamamoto H, Sekine Y, Sato Y, Higashizawa T, Miyata T, Iino S, Ido K, Sugano K: Total enteroscopy with a nonsurgical steerable double-balloon method. Gastrointest Endosc 2001;53:216-220.

8 Morris AJ, Madhok R, Sturrock RD, Capell HA, MacKenzie JF: Enteroscopic diagnosis of small bowel ulceration in patients receiving non-steroidal anti-inflammatory drugs. Lancet 1991;337:1093-1094.

-9 Fujimori S, Seo T, Gudis K, Tanaka S, Mitsui $\mathrm{K}$, Kobayashi T, Ehara A, Yonezawa $M$ Tatsuguchi A, Sakamoto C: Diagnosis and treatment of obscure gastrointestinal bleeding using combined capsule endoscopy and double-balloon endoscopy: 1-year follow-up study. Endoscopy 2007;39:1053-1058.
10 Matsumoto T, Kudo T, Esaki M, Yano T, Yamamoto H, Sakamoto C, Goto H, Nakase $\mathrm{H}$, Tanaka S, Matsui T, Sugano K, Iida M: Prevalence of non-steroidal anti-inflammatory drug-induced enteropathy determined by double-balloon endoscopy: a Japanese multicenter study. Scand J Gastroenterol 2008;43:490-496.

11 Kent TH, Cardelli RM, Stamler FW: Small intestinal ulcers and intestinal flora in rats given indomethacin. Am J Pathol 1969;54: 237-249.

12 Maiden L, Thjodleifsson B, Theodors A, Gonzalez J, Bjarnason I: A quantitative analysis of NSAID-induced small bowel pathology by capsule endoscopy. Gastroenterology 2005; 128:1172-1178.

13 Goldstein JL, Eisen GM, Lewis B, Gralnek IM, Zlotnick S, Fort JG: Video capsule endoscopy to prospectively assess small bowel injury with celecoxib, naproxen plus omeprazole, and placebo. Clin Gastroenterol Hepatol 2005;3:133-141. 
- 14 Sigthorsson G, Crane R, Simon T, Hoover M, 23 Bjarnason I, Smethurst P, Fenn CG, Lee CE, Quan H, Bolognese J, Bjarnason I: COX-2 inhibition with rofecoxib does not increase intestinal permeability in healthy subjects: a double-blind crossover study comparing rofecoxib with placebo and indomethacin. Gut 2000;47:527-532.

-15 Somasundaram S, Rafi S, Hayllar J, Sigthorsson G, Jacob M, Price AB, Macpherson A, Mahmod T, Scott D, Wrigglesworth JM, Bjarnason I: Mitochondrial damage: a possible mechanism of the 'topical' phase of NSAID-induced injury to the rat intestine. Gut 1997;41:344-353.

-16 Somasundaram S, Sigthorsson G, Simpson RJ, Watts J, Jacob M, Tavares IA, Rafi S, Roseth A, Foster R, Price AB, Wrigglesworth JM, Bjarnason I: Uncoupling of intestinal mitochondrial oxidative phosphorylation and inhibition of cyclooxygenase are required for the development of NSAID enteropathy in the rat. Aliment Pharmacol Ther 2000;14:639-650.

17 Goldstein JL, Eisen GM, Lewis B, Gralnek IM, Aisenberg J, Bhadra P, Berger MF: Small bowel mucosal injury is reduced in healthy subjects treated with celecoxib compared with ibuprofen plus omeprazole, as assessed by video capsule endoscopy. Aliment Pharmacol Ther 2007;15:1211-1222.

18 Hawkey CJ: Nonsteroidal anti-inflammatory drug gastropathy. Gastroenterology 2000; 119:521-535.

19 Miller TA: Protective effects of prostaglandins against gastric mucosal damage: current knowledge and proposed mechanisms. Am J Physiol 1983;245:G601-G623.

-20 Silverstein FE, Graham DY, Senior JR, Davies HW, Struthers BJ, Bittman RM, Geis GS: Misoprostol reduces serious gastrointestinal complications in patients with rheumatoid arthritis receiving nonsteroidal anti-inflammatory drugs. A randomized, double-blind, placebo-controlled trial. Ann Intern Med 1995;123:241-249.

-21 Gudis K, Samamoto C: The role of cycloxygenase in gastric mucosal protection. Dig Dis Sci 2005;50:S16-S23.

-22 Bjarnason I, Williams P, So A, Zanelli GD, Levi AJ, Gumpel JM, Peters TJ, Ansell B: Intestinal permeability and inflammation in rheumatoid arthritis: effects of non-steroidal anti-inflammatory drugs. Lancet 1984;2: 1171-1174. Menzies IS, Levi AJ: Misoprostol reduces indomethacin-induced changes in human small intestinal permeability. Dig Dis Sci 1989;34:407-411.

24 Fujimori S, Seo T, Gudis K, Ehara A, Kobayashi T, Mitsui K, Yonezawa M, Tanaka S, Tatsuguchi A, Sakamoto C: Prevention of NSAID-induced small intestinal injury by prostaglandin: a pilot randomized controlled trial evaluated by capsule endoscopy. Gastrointestinal Endosc 2009;69:1339-1346.

25 Graham DY, Opekun AR, Willingham FF Qureshi WA: Visible small-intestinal mucosal injury in chronic NSAID users. Clin Gastroenterol Hepatol 2005:3:55-59.

26 Watanabe T, Sugimori S, Kameda N, Machida H, Okazaki H, Tanigawa T, Watanabe K, Tominaga K, Fujiwara Y, Oshitani N, Higuchi K, Arakawa T: Small bowel injury by lowdose enteric-coated aspirin and treatment with misoprostol: a pilot study. Clin Gastroenterol Hepatol 2008;6:1279-1282.

27 Park SH, Cho CS, Lee OY, Jun JB, Lin SR, Zhou LY, Yuan YZ, Li ZS, Hou XH, Zhao HC, Kachintorn U, Kositchaiwat C, Lertkupinit C: Comparison of prevention of NSAID-induced gastrointestinal complications by rebamipide and misoprostol: a randomized, multicenter, controlled trial - Storm Study. J Clin Biochem Nutr 2007;40:148-155.

28 Terano A, Arakawa T, Sugiyama T, Suzuki H, Joh T, Yoshikawa T, Higuchi K, Haruma K, Murakami K, Kobayashi K, Rebamipide Clinical Study Group: Rebamipide, a gastroprotective and anti-inflammatory drug, promotes gastric ulcer healing following eradication therapy for Helicobacter pylori in a Japanese population: a randomized, doubleblind, placebo-controlled trial. J Gastroenterol 2007;42:690-693.

29 Kim HK, Kim JI, Kim JK, Han JY, Park SH, Choi KY, Chung IS: Preventive effects of rebamipide on NSAID-induced gastric mucosal injury and reduction of gastric mucosal blood flow in healthy volunteers. Dig Dis Sci 2007;52:1776-1782.

30 Sakurai K, Sasabe H, Koga T, Konishi T: Mechanism of hydroxyl radical scavenging by rebamipide: identification of monohydroxylated rebamipide as a major reaction product. Free Radic Res 2004;38:487-494.

31 Chitapanarux T, Praisontarangkul OA, Lertprasertsuke N: An open-labeled study of rebamipide treatment in chronic gastritis patients with dyspeptic symptoms refractory to proton pump inhibitors. Dig Dis Sci 2008; 53:2896-2903.

32 Mizoguchi H, Ogawa Y, Kanatsu K, Tanaka A, Kato S, Takeuchi K: Protective effect of rebamipide on indomethacin-induced intestinal damage in rats. J Gastroenterol Hepatol 2001;16:1112-1119.
33 Niwa Y, Nakamura M, Ohmiya N, Maeda O, Ando T, Itoh A, Hirooka Y, Goto H: Efficacy of rebamipide for diclofenac-induced smallintestinal mucosal injuries in healthy subjects: a prospective, randomized, doubleblinded, placebo-controlled, cross-over study. J Gastroenterol 2008;43:270-276.

34 Fujimori S, Seo T, Takahashi Y, Gudis K, Yamada Y, Tatsuguchi A, Ehara A, Kobayashi T, Mitsui K, Tanaka S, Sakamoto C: Prevention of NSAID-induced small intestinal injury by rebamipide: a prospective, doubleblind, randomized controlled trial using capsule endoscopy. Gastroenterology 2009; 136(suppl 1):A880.

-35 Fujimori S, Gudis K, Takahashi Y, Yamada Y, Seo T, Tatsuguchi A, Ehara A, Kobayashi T, Mitsui K, Tanaka S, Sakamoto C: Distribution of small intestinal mucosal injuries with short-term administration of non-steroidal anti-inflammatory drugs. Gastrointest Endosc 2009;69:AB100.

-36 Niwa Y, Nakamura M, Miyahara R, Ohmiya $\mathrm{N}$, Watanabe $\mathrm{O}$, Ando T, Kawashima H, Itoh A, Hirooka Y, Goto H: Geranylgeranylacetone protects against diclofenac-induced gastric and small intestinal mucosal injuries in healthy subjects: a prospective randomized placebo-controlled double-blind crossover study. Digestion 2009;80:260-266.

-37 Yanaka A, Zhang S, Sato D, Tauchi M, Suzuki H, Shibahara T, Matsui H, Nakahara A, Hyodo I: Geranylgeranylacetone protects the human gastric mucosa from diclofenacinduced injury via induction of heat-shock protein-70. Digestion 2007;75:148-155.

-38 Sakamoto C, Ogoshi K, Saigenji K, Narisawa R, Nagura H, Mine T, Tada M, Umegaki E, Maekawa T, Maekawa R, Maeda K: Comparison of the effectiveness of geranylgeranylacetone with cimetidine in gastritis patients with dyspeptic symptoms and gastric lesions: a randomized, double-blind trial in Japan. Digestion 2007;75:215-224.

39 Marchbank T, Limdi JK, Mahmood A, Elia G, Playford RJ: Clinical trial: protective effect of a commercial fish protein hydrolysate against indomethacin (NSAID)-induced small intestinal injury. Aliment Pharmacol Ther 2008;28:799-804

40 Fitzgerald AJ, Rai PS, Marchbank T, Taylor GW, Ghosh S, Ritz BW, Playford RJ: Reparative properties of a commercial fish protein hydrolysate preparation. Gut 2005;54:775781 . 